\title{
Authors' reply: Middle East respiratory syndrome coronavirus (MERS-CoV) in dromedary camels: are dromedary camels a reservoir for MERS-CoV?
}

N Nowotny (Norbert.Nowotny@vetmeduni.ac.at) ${ }^{1,2}$, J Kolodziejek ${ }^{1}$

1. Viral Zoonoses, Emerging and Vector-Borne Infections Group, Institute of Virology, University of Veterinary Medicine Vienna, Vienna, Austria

2. Department of Microbiology and Immunology, College of Medicine and Health Sciences, Sultan Qaboos University, Muscat, Oman

Citation style for this article:

Nowotny N, Kolodziejek J. Authors' reply: Middle East respiratory syndrome coronavirus (MERS-CoV) in dromedary camels: are dromedary camels a reservoir for MERS-CoV? . Euro Surveill. 2014;19(20):pii=20811. Available online: http://www.eurosurveillance.org/ViewArticle.aspx?Articleld=20811

Article submitted on 20 May 2014 / published on 22 May 2014

\section{To the Editor:}

We thank Karagöz et al. for their letter [1] in response to our paper [2]. The letter is a good opportunity to provide additional information on Middle East respiratory syndrome coronavirus (MERS-CoV) infection in dromedary camels and their potential role in the transmission of MERS-CoV to humans.

In fact, we mentioned in our paper [2] in detail that the cycle threshold $(\mathrm{Ct})$ values in nasal and conjunctival swabs of the five MERS-CoV reverse transcriptionquantitative polymerase chain reaction (RT-qPCR) positive Omani camels ranged from as low as 15.74 to 36.29 , indicating a high viral load in the former. Our results were confirmed in a recent report by Raj et al. [3], who demonstrated an even higher viral load (Ct values of 11.3 and 12.9) in a nasal swab of an eight-monthold camel from Qatar, sampled in February 2014. High loads of MERS-CoV nucleic acid in nasal swabs of dromedary camels from Saudi Arabia were also reported by Alagaili et al. [4].

Karagöz et al. [1] pointed out that we investigated specimens from the upper and not the lower respiratory tract, because MERS-CoV load has been reported to be less in upper respiratory tract samples than in lower respiratory tract samples. Although this is indeed true for human patients [5], who frequently develop during the course of a MERS-CoV infection, severe lower respiratory tract disease including pneumonia [6], infection in camels has been reported to be either asymptomatic [7] or associated with only mild respiratory signs with nasal discharge $[8,9]$. Consequently, the much easier - and nonetheless highly successoriented - way of sampling is taking nasal swabs, and so far, all studies investigating MERS-CoV in the respiratory tract of camels have been carried out on nasal swabs and not on lower respiratory tract specimens [2-4,7-10]. To further understand many aspects of MERS-CoV infection in camels, including pathogenesis, organ tropism, clinical symptoms, viral loads, and viral shedding, more studies are needed, both in the field and in controlled conditions.

The question of whether droplet or aerosol transmission of the MERS-CoV may occur is currently highly debated [5], mainly for human-to-human but also for camel-to-human transmission. Whether camels excrete and thereby may transmit MERS-CoV only in the form of droplets or also as aerosol can only be addressed in an experimental setting. Delineating the mode of respiratory transmission was not the goal of our study, and it is actually impossible in an epidemiological study to determine this; consequently, it cannot be considered a limitation of the study.

Despite a surge of reported human MERS-CoV infections during April and May 2014, which can be partly attributed to two healthcare-associated clusters and the detection of asymptomatic and mild cases through enhanced surveillance activities, it should be clearly noted that there is currently no risk of a human MERS$\mathrm{CoV}$ pandemic, since the basic reproductive rate of the virus $\left(R_{0}\right)$ is definitely below 1 and probably below 0.5 [11], which excludes sustained human-to-human transmission.

So far there is no report showing that infected camels secrete MERS-CoV in milk. In our opinion, there is no current need to apply regulatory measures on camel milk imports; however, the local population in certain regions should be convinced to abstain from drinking raw camel milk, not necessarily because of MERS-CoV but due to the risk of contracting brucellosis, Q-fever and other known zoonoses transmitted by dromedary camels [12]. We also think that camel meat does not really pose a risk for the consumer if standard hygienic procedures such as washing hands carefully after handling raw camel meat are applied; however, people 
slaughtering camels should be advised to wear protective gear, mask and glasses.

MERS-CoV infection in camels is widespread in the Arabian Peninsula, e.g., [13] and Africa [14]; consequently, trade restrictions would not be effective. In order to limit possible MERS-CoV transmission from camels to humans, a MERS-CoV vaccine for camels should be developed and applied to young camels after the levels of maternally derived antibodies decrease. No one has been suggesting culling of camels because of MERS since there is no reason at all for such an approach.

We do apologise that we were unable to report data on age, clinical status, geographical area of sampling, and travel history of the MERS-CoV nucleic acid positive camels, as these data were not provided to us.

Human infections resulting from (probably very close direct) contact with acutely infected camels have been shown [8], and such cases may be the source of limited human-to-human transmissions. However, the vast majority of MERS-CoV transmissions seem to occur within families [15], in the community [16] and in healthcare facilities [15], which especially raise a serious concern. In addition, in a growing number of infected people, the source of infection remains unclear.

We are only at the beginning of our understanding of MERS, and we fully agree that there are still many open questions, including the epidemiological role of camels and the MERS-CoV transmission routes. These unknown areas need to be addressed in joint efforts by the national medical and veterinary authorities of the affected countries, research institutions, and internationally coordinated by the World Health Organization (WHO), the Food and Agriculture Organization of the United Nations (FAO), and the World Organisation for Animal Health (OIE).

\section{Conflict of interest}

None declared.

Authors' contributions

NN wrote the manuscript; JK read and revised the manuscript.
4. Alagaili AN, Briese T, Mishra N, Kapoor V, Sameroff SC, Burbelo PD, et al. Middle East respiratory syndrome coronavirus infection in dromedary camels in Saudi Arabia. MBio. 2014;5(2):eoo884-14. http://dx.doi.org/10.1128/mBio.01002-14

5. Memish ZA, Al-Tawfiq JA, Makhdoom HQ, Assiri A, Alhakeem RF, Albarrak A, et al. Respiratory tract samples, viral load and genome fraction yield in patients with Middle East respiratory syndrome. J Infect Dis. 2014 May 15 [Epub ahead of print]. http://dx.doi.org/10.1093/infdis/jiu292

6. Assiri A, Al-Tawfiq JA, Al-Rabeeah AA, Al-Rabiah FA, Al-Hajjar S, Al-Barrak A, et al. Epidemiological, demographic, and clinical characteristics of 47 cases of Middle East respiratory syndrome coronavirus disease from Saudi Arabia: a descriptive study. Lancet Infect Dis. 2013;13(9):752-61. http://dx.doi. org/10.1016/S1473-3099(13)70204-4

7. Chu DKW, Poon LLM, Gomaa MM, Shehata MM, Perera RAPM, Zeid DA, et al. MERS coronaviruses in dromedary camels, Egypt. Emerg Infect Dis. 2014;20(6):1049-53. http://dx.doi. org/10.3201/eid2006.140299

8. Memish ZA, Cotten M, Meyer B, Watson SJ, Alsahafi AJ, Al Rabeeah AA, et al. Human infection with MERS coronavirus after exposure to infected camels, Saudi Arabia, 2013. Emerg Infect Dis. 2014;20(6):1012-5. http://dx.doi.org/10.3201/ eid2006.140402

9. Hemida MG, Chu DKW, Poon LLM, Perera RAPM, Alhammadi $\mathrm{MA}, \mathrm{Ng} \mathrm{H}-\mathrm{Y}$, et al. MERS coronavirus in dromedary camel herd, Saudi Arabia. Emerg Infect Dis. 2014. Jul [Epub ahead of print]. http://dx.doi.org/10.3201/eid2007.140571

10. Haagmans BL, Al Dhahiry SH, Reusken CB, Raj VS, Galiano M, Myers R, et al. Middle East respiratory syndrome coronavirus in dromedary camels: an outbreak investigation. Lancet Infect Dis. 2014;14(2):140-5. http://dx.doi.org/10.1016/ S1473-3099(13)70690-X

11. Memish ZA, Al-Tawfiq J, Drosten C, Assiri A, Alhakeem R, Albarrak A, et al. Middle East respiratory syndrome Corona virus, MERS-CoV. Conclusions from the 2 nd Scientific Advisory Board Meeting of the WHO Collaborating Center for Mass Gathering Medicine, Riyadh. Int J Infect Dis. 2014 May 10. [Epub ahead of print]. http://dx.doi.org/10.1016/j. ijid.2014.05.001

12. Afzal M, Sakkir M. Survey of antibodies against various infectious disease agents in racing camels in Abu Dhabi, United Arab Emirates. Rev Sci Tech. 1994;13(3):787-92.

13. Reusken CB, Haagmans BL, Müller MA, Gutierrez C, Godeke GJ, Meyer B, et al. Middle East respiratory syndrome coronavirus neutralising serum antibodies in dromedary camels: a comparative serological study. Lancet Infect Dis. 2013;13(10):859-66. http://dx.doi.org/10.1016/ S1473-3099(13)70164-6

14. Reusken CBEM, Messadi L, Feyisa A, Ularamu H, Godeke G-J, Danmarwa A, et al. Geographic distribution of MERS coronavirus among dromedary camels, Africa. Emerg Infect Dis. 2014; Jul [Epub ahead of print]. http://dx.doi.org/10.3201/ eid2007.140590

15. Memish ZA, Al-Tawfiq JA, Makhdoom HQ, Al-Rabeeah AA, Assiri A, Alhakeem RF, et al. Screening for Middle East respiratory syndrome coronavirus infection in hospital patients and their healthcare worker and family contacts: a prospective descriptive study. Clin Microbiol Infect. 2014 Jan 24 [Epub ahead of print]. http://dx.doi.org/10.1111/1469-0691.12562

16. Memish ZA, Cotten M, Watson SJ, Kellam P, Zumla A, Alhakeem RF, et al. Community case clusters of Middle East respiratory syndrome coronavirus in Hafr Al-Batin, Kingdom of Saudi Arabia: a descriptive genomic study. Int J Infect Dis. 2014 Mar 31 [Epub ahead of print]. http://dx.doi.org/10.1016/j. ijid.2014.03.1372

References

1. Karagöz E, Hatipoğlu M, Turhan V. Letter to the Editor: Middle East respiratory syndrome coronavirus (MERS-CoV) in dromedary camels: are dromedary camels a reservoir for MERS-CoV? . Euro Surveill. 2014;19(20). pii $=20810$.

2. Nowotny N, Kolodziejek J. Middle East respiratory syndrome coronavirus (MERS-CoV) in dromedary camels, Oman, 2013. Euro Surveill. 2014;19(16). pii: 20781.

3. Stalin Raj V, Farag EABA, Reusken CBEM, Lamers MM, Pas SD, Voermans J, et al. Isolation of MERS coronavirus from dromedary camel, Qatar, 2014. Emerg Infect Dis 2014 Aug [Epub ahead of print]. http://dx.doi.org/10.3201/ eid2008.140663 